\title{
Reproductive biology of the intertidal and infralittoral mysids Archaeomysis kokuboi and A. japonica on a sandy beach in NE Japan
}

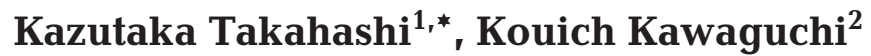 \\ ${ }^{1}$ Tohoku National Fisheries Research Institute, 3-27-5 Shinhama, Shiogama, Miyagi 985-0001, Japan \\ ${ }^{2}$ Ocean Research Institute, University of Tokyo 1-15-1 Minamidai, Nakano, Tokyo 164-8639, Japan
}

\begin{abstract}
Seasonal reproductive biology was investigated in 2 species of Archaeomysis, each of which occurs in distinctive habitats, intertidal and infralittoral areas of a sandy beach of NE Japan. The seasonal reproductive patterns of the 2 species are similar, with 3 breeding peaks from spring to autumn. The populations are initially dominated by larger sized overwintering and then smaller sized spring/summer generations. However, intertidal A. kokuboi exhibits a more extended breeding period than infralittoral $A$. japonica. The brood size (number of Stage I larvae female ${ }^{-1}$ ) increased with increasing size of females and averaged 12 to 72 for $A$. kokuboi and 10 to 55 for A. japonica, showing a higher brood size in the overwintering individuals of $A$. kokuboi. The larval size and development time and the interval between broods decreased with increasing temperature; and development took much longer in A. japonica at the lower temperature range. In overwintering generations, the larval (Stage I) production rate of $A$. kokuboi (0.9 to 3.4 larvae female $\left.{ }^{-1} \mathrm{~d}^{-1}\right)$ was higher than in A. japonica (0.6 to 2.1), while after July the rate of both species fluctuated in almost the same range $(0.4$ to 1.9$)$. The specific larval production rate of both species was significantly related to water temperature and was 17 to $38 \%$ higher in A. kokuboi than in A. japonica throughout the year. This study found that $A$. kokuboi retains a higher reproductive effort to settle into the intertidal zone of sandy beaches, but does not show any specialization to the basic reproductive features, such as an altered generation pattern or a change in larval size. The retention of a high reproductive potential in A. kokuboi is an adaptation to the intertidal zone of sandy beaches which is characterized by a high mortality rate due to unpredictable events such as storms, while efficient reproduction during the high water temperature season in A. japonica is an adaptation to the infralittoral habitat where more predictable events, such as seasonal variation of temperature, prevail as environmental variables.
\end{abstract}

KEY WORDS: Reproduction · Life history · Fecundity · Larval development $\cdot$ Larval production Interval between broods $\cdot$ Gastrosaccinae $\cdot$ Mysida

\section{INTRODUCTION}

Of the many marine environments populated by macroscopic animal life, sandy beaches, particularly the wave-washed swash zone of the beach face, are one of the most dynamic habitats. This environment is physically rigorous, subject not only to extreme ranges of air and sea temperature, salinity and desiccation, but especially to the constant movement of water and substratum through the action of waves and tidal currents. Nevertheless, this area has been in particular colonized by species of Crustacea and Mollusca well adapted to the physically rigorous nature of these dynamic environments (Brown \& McLachlan 1990). During the process of invasion into this habitat, these macrofauna species have evolved behavioral, morphological and physiological adaptations to withstand the harsh physical conditions (e.g. Cubit 1969, Kamihira 
1979, Brown 1983, Ellers 1995a,b,c, Dugan et al. 2000). Together with these adaptations, life history traits must also be assumed to reflect the adaptations against the harsh physical conditions. In terms of reproductive biology, because of the physical harshness and unpredictable fluctuations of environmental variables, the inhabitants on intertidal sandy beaches have been hypothesized to exhibit an early maturity and higher reproductive output (e.g. Veloso \& Cardoso 1999, Souza \& Borzone 2000). On the other hand, settlement into the intertidal beach obliges the macrofauna to expend much energy due to further adaptation such as intertidal migration (McLachlan et al. 1979, Takahashi \& Kawaguchi 1997), osmotic regulation (Webb et al. 1997), reinforcement of the exoskelton (Kamihira 1979, Brown 1982, Takahashi 1996), and in terms of energy budget these extra costs are expected to have negative effects on their reproduction. Although a number of studies on the reproductive biology of intertidal macrofauna have been made (e.g. Diaz 1980, Defeo et al. 2001), these mostly deal with a single species which exhibits high adaptation to the intertidal, thus possibly concealing the effect of the environment on the development of life history traits. In this context, to understand the reproductive strategy of intertidal species on sandy beaches, direct comparisons of reproductive traits between closely related species which live in intertidal and infralittoral areas at the same beach are needed. However, few studies to date have been made (e.g. Fish \& Preece 1970, De Ruyck et al. 1991).

The mysids belonging to the genus Archaeomysis, subfamily Gastrosaccinae, consist of sand burrowers, which have been recorded from the temperate and subarctic waters of the North Pacific (Ii 1964, Mauchline \& Murano 1977, Jo \& Hanamura 1993, Hanamura et al. 1996, Hanamura 1997). They are often overwhelmingly predominant and are known to be an important trophic resource to surf zone fishes, crustaceans and shore birds (Matsudaira et al. 1952, Hanamura 1997, 1999, Takahashi et al. 1999, Takahashi \& Kawaguchi 2001, Kaneko \& Omori 2003). Five Archaeomysis species have been recorded around Japan and they are divided into 2 groups according to their habitat, i.e. intertidal and infralittoral inhabitants (Hanamura 1997). Two Archaeomysis species, Archaeomysis kokuboi Ii and Archaeomysis japonica Hanamura, Jo \& Murano, occur on the same beach of Otsuchi Bay, off the Pacific coast of northeastern Japan and have been shown to have developed clear interspecific zonation in nearshore waters, i.e. A. kokuboi occupies the swash zone, whereas A. japonica inhabits the infralittoral zone (Takahashi \& Kawaguchi 1995). Although these 2 congeneric mysids are very similar in morphology and size (Ii 1964, Takahashi \& Kawaguchi 1996), the density of A. kokuboi is substantially higher than A. japonica in Otsuchi Bay throughout the year (Takahashi \& Kawaguchi 1995). Factors suggested as important for supporting the high abundances of $A$. kokuboi include habitat characteristics of the intertidal zone, resulting in a rich accumulation of food (phytoplankton, copepods) and protection from predators (Takahashi \& Kawaguchi 1998, Takahashi et al. 2004). However, information regarding the reproductive biology, which is essential to determine their recruitment, is still unknown.

In this study, we determined seasonal reproductive traits of the 2 closely related mysids. First, their population structure, breeding periodicity, size at maturity, brood size, size of Stage I larva, larval development time, and larval production rate were compared through field surveys and laboratory experiments, and then all the reproductive parameters were integrated into an empirical reproduction model in order to evaluate the questions: (1) do intertidal species have a higher potential to reproduce than their infralittoral congener? (2) do intertidal beach habitats affect the reproductive parameters of the inhabitant?

\section{MATERIALS AND METHODS}

The study was performed at Koshirahama Beach in Otsuchi Bay off the Pacific coast of northern Honshu $\left(39^{\circ} 21^{\prime} \mathrm{N}, 141^{\circ} 52^{\prime} \mathrm{E}\right)$. Koshirahama Beach is a small sandy beach, $120 \mathrm{~m}$ long and bordered by rocky shores at both ends. The beach is categorized as a sheltered beach according to McLachlan's rating scheme for assessing the degree of exposure of sandy beaches (Brown \& McLachlan 1990). The median particle diameter of the sand is about $260 \mu \mathrm{m}$ and the beach slope is 1:13 in the intertidal habitat. Mean depths at sampling points 20,50 and $100 \mathrm{~m}$ from the shoreline were 1.6, 3.5 and $5.5 \mathrm{~m}$, respectively.

Sampling was carried out monthly with a sledge net (60 cm width, $40 \mathrm{~cm}$ height, $200 \mu \mathrm{m}$ mesh size) from January 1992 to January 1993. Ten successive $10 \mathrm{~m}$ tows were made along a $100 \mathrm{~m}$ transect perpendicular to the shoreline and 10 samples were collected at a time. To reduce the effect of the sea condition and tide, sampling was carried out on calm days around the lowest level of the spring tide and the tide level at sampling changed from $0 \mathrm{~cm}$ on June 30 to $100 \mathrm{~cm}$ on November 24 above the datum, $86 \mathrm{~cm}$ below mean sea level. The samples were fixed in $10 \%$ formalin. Along the transect line, the temperature and salinity just above the bottom were measured every $10 \mathrm{~m}$ with an STD probe (Alec Electronics, AST-1000S).

All Archaeomysis kokuboi and A. japonica were sorted into groups of different sexual maturity based on Mauchline (1980) under a stereo microscope. 
Brooding females were separated each month and the standard length was measured $(S L, \mathrm{~mm}$ : distance from the base of the eyestalk to the distal end of the 6th abdominal segment). Body carbon weight of a female $\left(C_{\mathrm{F}}, \mathrm{mg}\right)$ was converted from the $S L$ using the equations given by Takahashi (1996) (see Table 1, Fig. 3a).

Marsupial larvae in brooding females were staged, measured and counted. Staging of the larva was based on Mauchline (1980), i.e. Stage I: egg-shaped larvae; Stage II: eyeless larvae; Stage III: eyed larvae. The diameter of 10 Stage I larvae per brood was measured with a profile projector (Mitsutoyo PJ 311). The freshly released Stage I larvae in the marsupium closely resemble the ripe eggs within the oviduct in size (Mauchline 1980) and are spherical or sub-spherical in shape. Since loss of larvae during development is well known in mysids (Mauchline 1973, 1980, Wittmann 1984), brooding females which have Stage II and III larvae were not used for fecundity analysis (brood size and relative fecundity) and as a result, data of the fecundity from some samples, i.e. Jan 1992 for Archaeomysis kokuboi, late June for the larger size class of $A$. japonica of which brooding female exclusively had advanced stage larvae (Stage II, III), were not available.

The relationships between Stage I larva diameter $(L D, \mathrm{~mm})$ and carbon content of single Stage I larvae $\left(C_{\mathrm{L}}, \mathrm{mg}\right)$ were determined from field-collected brooding females of both species in March, April, May and September 1997. Broods were removed from marsupia of brooding females with forceps and a gentle water current from a pipette. The Stage I larvae were counted and measured for mean diameter using the same procedure mentioned above. After rinsing with distilled water, 1 to 3 broods, ca. 20 to 80 Stage I larvae were placed onto a pre-combusted and preweighted glass-fiber filter (Whatman GF/C). They were dried at $60^{\circ} \mathrm{C}$ for $48 \mathrm{~h}$ to determine the dry weight of a single Stage I larva and analyzed for carbon content with a $\mathrm{CN}$ analyzer (Fisons model EA1108 CHNS/O).

In situ Stage I larval production rate $(L P R$, Stage I larvae female ${ }^{-1} \mathrm{~d}^{-1}$ ) was determined for each sampling:

$$
L P R=B S_{\mathrm{F}} /\left(D_{\mathrm{L}}+I_{\mathrm{B}}\right)
$$

where $B S_{\mathrm{F}}$ is the mean brood size of the field population, $D_{\mathrm{L}}$ is the larval development time (d) and $I_{\mathrm{B}}$ is the time interval between successive broods (d). The duration of the larval development time in relation to the temperature was investigated in April and September 1995 using the various stages of larvae (Stage I to III) which were removed using the procedure mentioned above from field-collected brooding females. The larvae were incubated at 9 different temperatures; 6,7 , 10, 12 (in April) and 13, 16, 18, 20, $22^{\circ} \mathrm{C}$ (in September) for Archaeomysis kokuboi, and 6, 8, 10, 13 (in April) and $14,16,18,20,22^{\circ} \mathrm{C}$ (in September) for Archaeomysis japonica. At each temperature, larvae from a single brood were incubated in a glass petri dish with filtered seawater (with a $0.45 \mu \mathrm{m}$ filter), which was replaced every 1 to $2 \mathrm{~d}$ with freshly collected water. In all experiments, the development time for each larval stage was measured separately and the succession of the stage was determined with moulting of the larvae (Matsudaira et al. 1952). The larvae were checked daily and the day on which half of the larvae had moulted to the next stage was defined as the day of succession to the next stage. Finally, the development time for each stage was summed as the total larval development time.

The interval between broods, i.e. the duration from release of juveniles to the ovulation of the next brood was measured in May (for $10^{\circ} \mathrm{C}$ ), June $\left(15^{\circ} \mathrm{C}\right)$, August $\left(20^{\circ} \mathrm{C}\right)$ and September $\left(23^{\circ} \mathrm{C}\right)$ for Archaeomysis kokuboi; June $\left(12^{\circ} \mathrm{C}\right)$, July $\left(17^{\circ} \mathrm{C}\right)$, August $\left(20^{\circ} \mathrm{C}\right)$ and September $\left(23^{\circ} \mathrm{C}\right)$ for Archaeomysis japonica, using field-caught females with late stage larvae in their marsupia. In the laboratory, individual females were incubated in a 31 plastic transparent tank with 2 to 3 mature males. The nauplii of Artemia or the natural zooplankton assemblage were added as food and half of the seawater was replaced daily with freshly collected water. The tanks were maintained under a 12:12 h light:dark cycle. Every morning, the release of juveniles, cast of moults and the extrusion of the next brood into the brood pouch were checked.

To offset the effect of variation on female body size or larval size, specific Stage I larval production rate $\left(S L P R, \mathrm{~d}^{-1}\right)$ was also determined:

$$
S L P R=L P R \times C_{\mathrm{L}} / C_{\mathrm{F}}
$$

where $C_{\mathrm{L}}$ and $C_{\mathrm{F}}$ are mean carbon weight $(\mathrm{mg})$ of a Stage I larva and brooding female for each sampling, respectively.

\section{RESULTS}

\section{Environmental conditions}

Monthly variations of temperature and salinity in the natural habitat of adult female Archaeomysis kokuboi and A. japonica are shown in Fig. 1. Almost all adult females of $A$. kokuboi were consistently distributed within $10 \mathrm{~m}$ from the shoreline, while $A$. japonica occurred in the range of 10 to $70 \mathrm{~m}$ from the shoreline throughout the sampling period (see also Takahashi \& Kawaguchi 1995) and therefore, the values are shown as the mean of the sampling point, corresponding to their main habitat. 


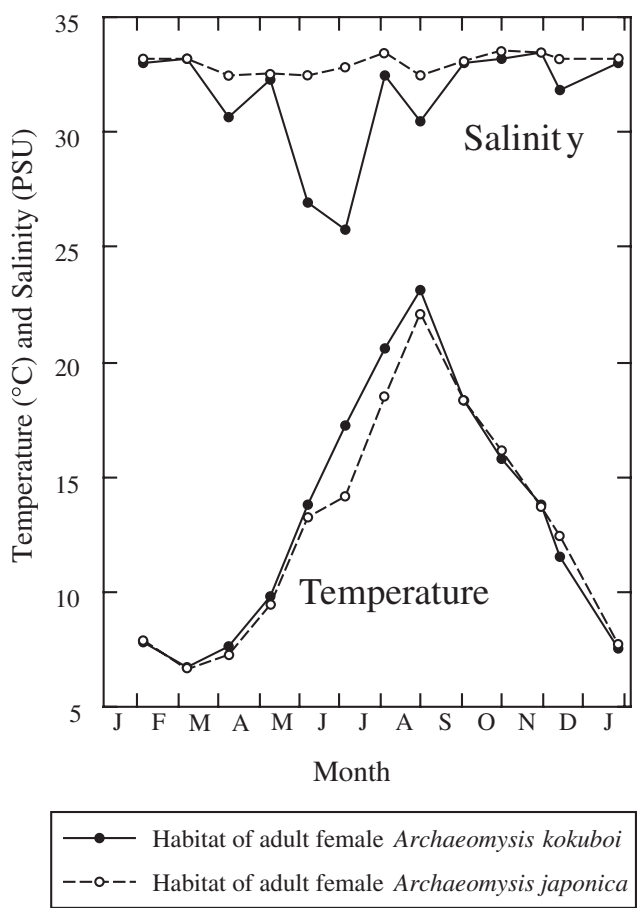

Fig. 1. Archaeomysis kokuboi and A. japonica. Temperature and salinity at the habitat of adult females at Koshirahama Beach in Otsuchi Bay. Values are the mean of the sampling point, corresponding to their main habitat

Temperature was significantly different between Month (2-way ANOVA, $\left.F_{12,26}=10213.74, \mathrm{p}<0.001\right)$ and Habitat $\left(F_{1,26}=271.6, \mathrm{p}<0.001\right)$, and in the 'Month $\times$ Habitat' interaction $\left(F_{12,26}=105.93, \mathrm{p}<0.001\right)$. Temperature in both habitats showed a similar fluctuation pattern; it was lowest on 3 March at $7.6^{\circ} \mathrm{C}$ and then increased to the annual peak on 26 August to 23.5 and $22.1^{\circ} \mathrm{C}$ for the habitats of $A$. kokuboi and A. japonica, respectively (Fig. 1). During the period of increasing temperature (April to August), the temperature at the habitat of $A$. kokuboi was always higher than that of $A$. japonica (Wilcoxon test, $\mathrm{p}<0.05$ ).

Salinity was significantly different between Month (2-way ANOVA, $\left.F_{12,26}=10.98, \mathrm{p}<0.001\right)$ and Habitat $\left(F_{1,26}=45.56, \mathrm{p}<0.001\right)$, and in the 'Month $\times$ Habitat' interaction $\left(F_{12,26}=7.46, \mathrm{p}<0.001\right)$. Salinity in the habitat of A. kokuboi (26.3 to 33.4) was considerably more variable than in the habitat of A. japonica (32.1 to 33.2), and it was lower and more variable in spring and summer than in autumn and winter.

\section{Monthly variation in population density and composition}

The 2 species of Archaeomysis showed a similar pattern in the monthly variation in density and their densities were significantly different between sampling time and species (2-way ANOVA, $F_{11,36}=99.72$, $\mathrm{p}<0.001$ for Month; $F_{1,36}=419.5, \mathrm{p}<0.001$ for Species; $F_{11,36}=78.36, \mathrm{p}<0.001$ for 'Species $\times$ Month'). The population density of $A$. kokuboi varied from 79 in March to 5105 ind. $\mathrm{m}^{-2}$ in July (Fig. 2a). In spring, densities were low, 79 to 190 ind. $\mathrm{m}^{-2}$ and increased to 784 to 5105 ind. $\mathrm{m}^{-2}$ during June to July. In August, A. kokuboi decreased to 113 ind. $\mathrm{m}^{-2}$, after which it gradually increased to reach a second peak of 2160 ind. $\mathrm{m}^{-2}$ during December. Brooding females of $A$. kokuboi occurred throughout the year, but their proportion in the population increased in April to May, July to August and November. These 3 seasons are probably the main breeding periods of $A$. kokuboi, since the increase in the brooding females was followed by increases in the proportion of juveniles (Fig. 2b).

The density of Archaeomysis japonica varied from 6 in May to 522 ind. $\mathrm{m}^{-2}$ in November (Fig. 2a). In spring, the density fluctuated at a low level around 6 to 10 ind. $\mathrm{m}^{-2}$, but it increased markedly to 151 to 294 ind. $\mathrm{m}^{-2}$ from June to July, mainly due to recruitment by juveniles (Fig. 2c). From August to October, densities decreased to 14 to 26 ind. $\mathrm{m}^{-2}$, but from November to December, increased again to 273 to 522 ind. $\mathrm{m}^{-2}$. Brooding females of A. japonica did not occur during January to March when the water temperature was low. Judging from the proportion of brooding females in the population, May, August and October would be the main breeding periods of $A$. japonica (Fig. 2c).

\section{Size of brooding females}

Large brooding females of both species occurred from March to early June. Females of Archaeomysis kokuboi had a brood at 11.6 to $12.1 \mathrm{~mm}$ in $S L$ (2.8 to $3.3 \mathrm{mg}$ body carbon) during the period from March to early June (Fig. 3a). By the end of June, the size of brooding females of $A$. kokuboi had decreased to $9 \mathrm{~mm}$ $(1.2 \mathrm{mgC})$ and it continued to decrease to $7.0 \mathrm{~mm}$ $(0.6 \mathrm{mgC})$ in September. From September to January 1993, the size of brooding females of A. kokuboi increased gradually and reached $8.7 \mathrm{~mm}(1.1 \mathrm{mgC})$ in January.

Although Archaeomysis japonica had a brood at almost the same size of A. kokuboi in SL (11.5 to $12.1 \mathrm{~mm}$ ) during the period from April to early June, their body carbon weight (2.6 to $2.9 \mathrm{mgC}$ ) was significantly (ca. 5 to $25 \%$ ) lower than that of $A$. kokuboi during the same period (ANOVA $F_{1,509}=9.98 ; \mathrm{p}<$ 0.002 ), because the standard length-carbon weight relationship differs between species (Fig. 3b; ANCOVA, 
$\left.F_{1,146}=4.63 ; \mathrm{p}<0.05\right)$. At the end of June, 2 size groups of brooding females in A. japonica, i.e. larger $(11 \mathrm{~mm}, 2.4 \mathrm{mgC})$ and smaller $(9 \mathrm{~mm}, 1.3 \mathrm{mgC})$ females were recognized. Since the larger sized females had exclusively Stage III larvae, they were regarded as the remainder of larger sized females. In July, the size of brooding females of A. japonica decreased to $8.7 \mathrm{~mm}(1.1 \mathrm{mgC})$ and from August to October, it leveled off at around $8.3 \mathrm{~mm}(1.0 \mathrm{mgC})$, of which carbon contents were consistently higher than those of A. kokuboi for the same period (ANOVA $\left.F_{1,369}=13.5 ; \mathrm{p}<0.003\right)$. From November to December, the size of brooding females of $A$. japonica decreased again to around $7.8 \mathrm{~mm}(0.8 \mathrm{mgC})$ and this was in contrast to $A$. kokuboi over the same period where the size increased with decreasing water temperature (Fig. 3a).
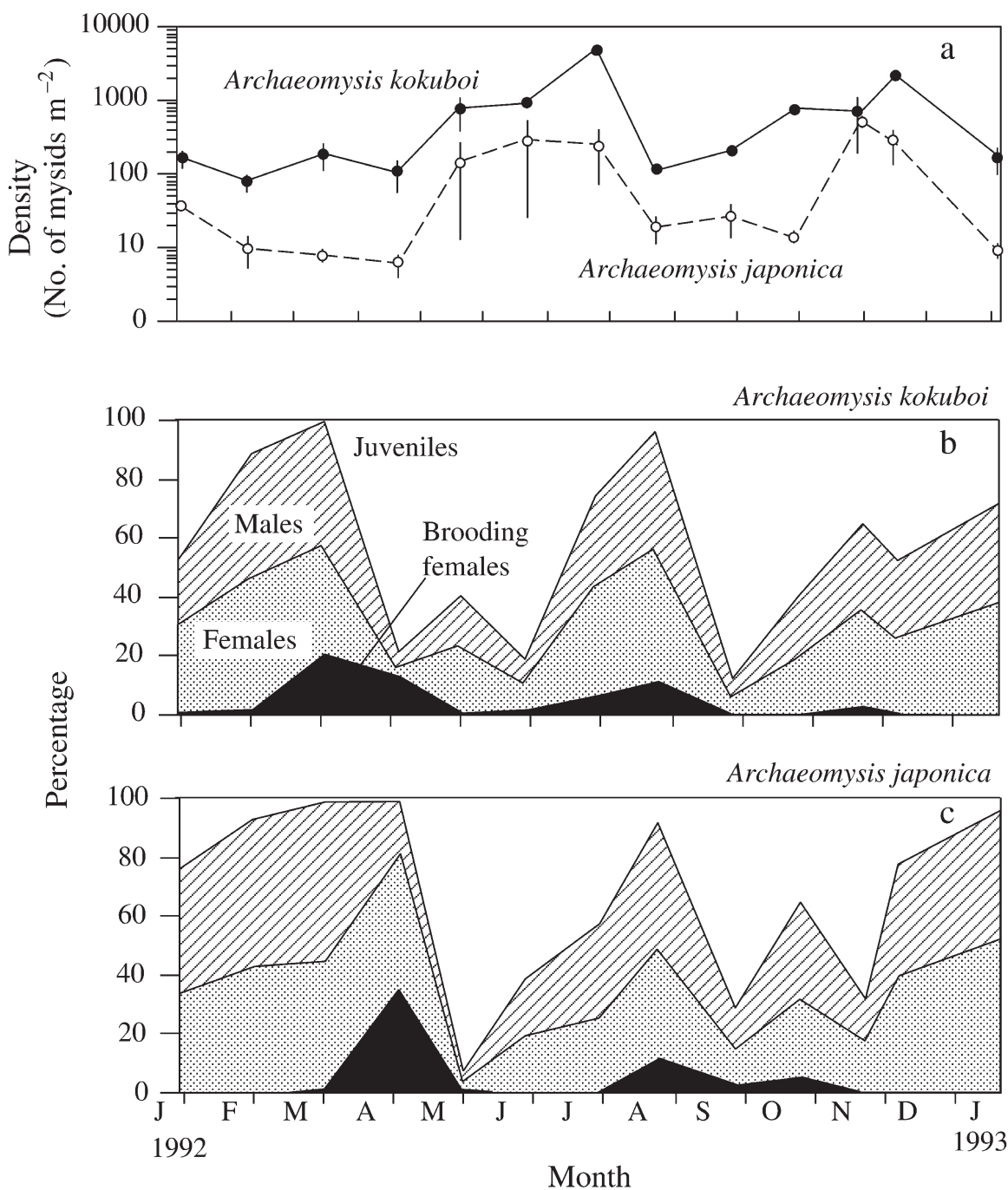

Fig. 2. Archaeomysis kokuboi and A. japonica. Seasonal variation in (a) density, (vertical bars indicate $\mathrm{SD}$ ) and $(\mathrm{b}, \mathrm{c})$ population composition at Koshirahama Beach in Otsuchi Bay

\section{Brood size and size of Stage I larvae}

In both species, the monthly variation of mean brood size (number of Stage I larvae female ${ }^{-1}$ ) showed a similar pattern, i.e. it was high in spring and decreased in summer and autumn (Fig. 4a). During spring, the mean brood size of Archaeomysis kokuboi was 49 in March and it increased with the progress of time and in early June, the mean brood size reached its annual maximum, 72. At the end of June, the brood size of $A$. kokuboi decreased to 32 and continued to decrease to 19 in August. In September and October, the brood size increased again to 23 to 25 . However, it dropped to $<16$ after November (Fig. 4a).

In Archaeomysis japonica, the mean brood size was 40 in March and it also increased with time, and in early June the mean brood size reached its annual maximum, 55. During spring, the brood size of A. japonica was consistently ca. $20 \%$ lower than that of $A$. kokuboi (Fig. 4a). At the end of June, the brood size of $A$. japonica decreased to 26 and then it fluctuated around 20 to 24 until October; it dropped to $<16$ after November.

The monthly variations in brood size were fundamentally related to the monthly variation of parental size (Fig. 4b) and the brood size for Archaeomysis kokuboi was significantly higher than for A. japonica (ANCOVA $F_{1,294}=8.09 ; \mathrm{p}<0.005$ ). However, among brooding females of the same size class, the brood size often exhibited wide seasonal variations (Fig. 5a,b). Specifically, the variations were great in large females during spring; for instance, the mean brood sizes in the overwintering generation increased by about $30 \%$ in both species during the period from March/April to early June (Fig. 5a,b). The variation was largely caused by the change of size of Stage I larvae, which was inversely related to water temperature (Fig. 5c,d) since the relative fecundity (ratio of brood carbon to parental body carbon) did not show a tendency to increase during this period (see Fig. 6). No statistical difference (paired $t$-test) was found in the size of Stage I larvae between both species at any sampling time. The diameter of Stage I larvae $(L D, \mathrm{~mm})$ showed significant relationships with temperature $\left(T,{ }^{\circ} \mathrm{C}\right)$ in their 

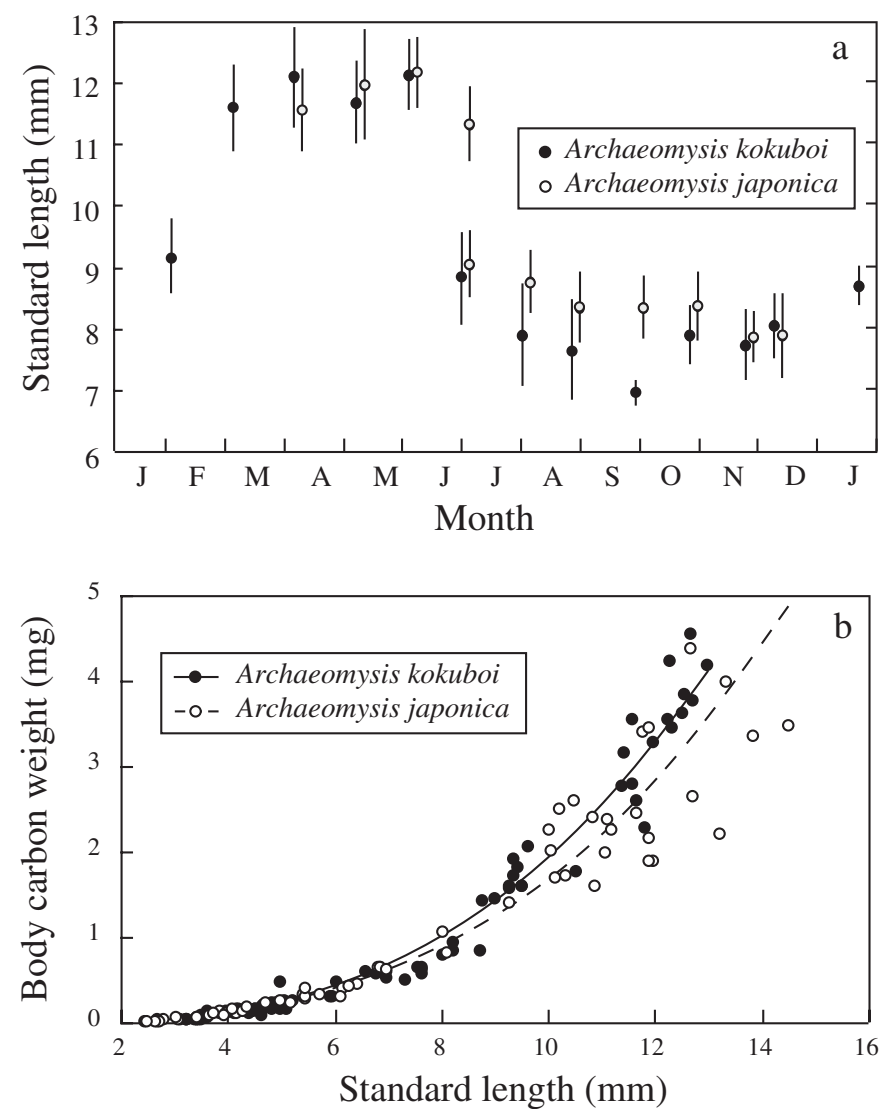

Fig. 3. Archaeomysis kokuboi and A. japonica. (a) Seasonal variation of standard length $(\mathrm{mm})$ in brooding females at Koshirahama Beach in Otsuchi Bay. Vertical bars indicate SD. Two different size groups were found for A. japonica at the end of June (see text). (b) Standard length-body carbon weight relationships obtained from field collected samples. Regressions are given in Table 1

habitat but no statistical difference was found between 2 species (Eqs. $3 \& 4$ in Table 1). Therefore, to best illustrate the brood size (BS), Eqs. (5) \& (6) in Table 1 were derived by multiple regression analysis with standard length of brooding female $(S L)$ and diameter of Stage I larvae $(L D)$ as independent values. Carbon content of a single Stage I larva $\left(C_{\mathrm{L}}, \mathrm{mg}\right)$ was well related with the diameter $(L D)$ in both species (Eqs. 7 \& 8 in Table 1).

\section{Relative fecundity}

Based on their brood size, diameter of Stage I larvae and parental size, relative fecundity (ratio of brood carbon to parental body carbon) of brooding females was calculated (Fig. 6). 2-way ANOVA revealed significant differences in the ratio between Species $\left(F_{1,318}=18.09\right.$; $\mathrm{p}<0.001)$ and Month $\left(F_{9,318}=11.41 ; \mathrm{p}<0.001\right)$, while the 'Species $\times$ Month' interaction did not $\left(F_{9,318}=1.67\right.$; $\mathrm{p}=0.1$ ). From early March to May, Archaeomysis kokuboi maintained a higher investment of carbon to their broods and the mean ratios were constant around 0.53 (Fig. 6). In early June, the mean ratio decreased to 0.38 , though the size of brooding females was still large, similar to those in March to May (Fig. 3). Thereafter, the ratios of smaller size females leveled off at around 0.35 to 0.40 from late June to November with the exception of October where the mean ratio showed 0.45. From December to January, the mean ratios fluctuated around a slightly lower level at around 0.25 to 0.28 .

Although Archaeomysis japonica also showed a higher investment of carbon to their broods in spring time (April to May), their mean ratios, 0.41 to 0.44 were lower than those of $A$. kokuboi during the same period (ANOVA, $\left.F_{1,69}=5.02 ; \mathrm{p}<0.05\right)$. A decrease of the relative fecundity in larger size females was also observed in early June; the ratio dropped to 0.37 . From July to November, the ratios in females which attained maturity at smaller size, varied from 0.34 to 0.40 , with

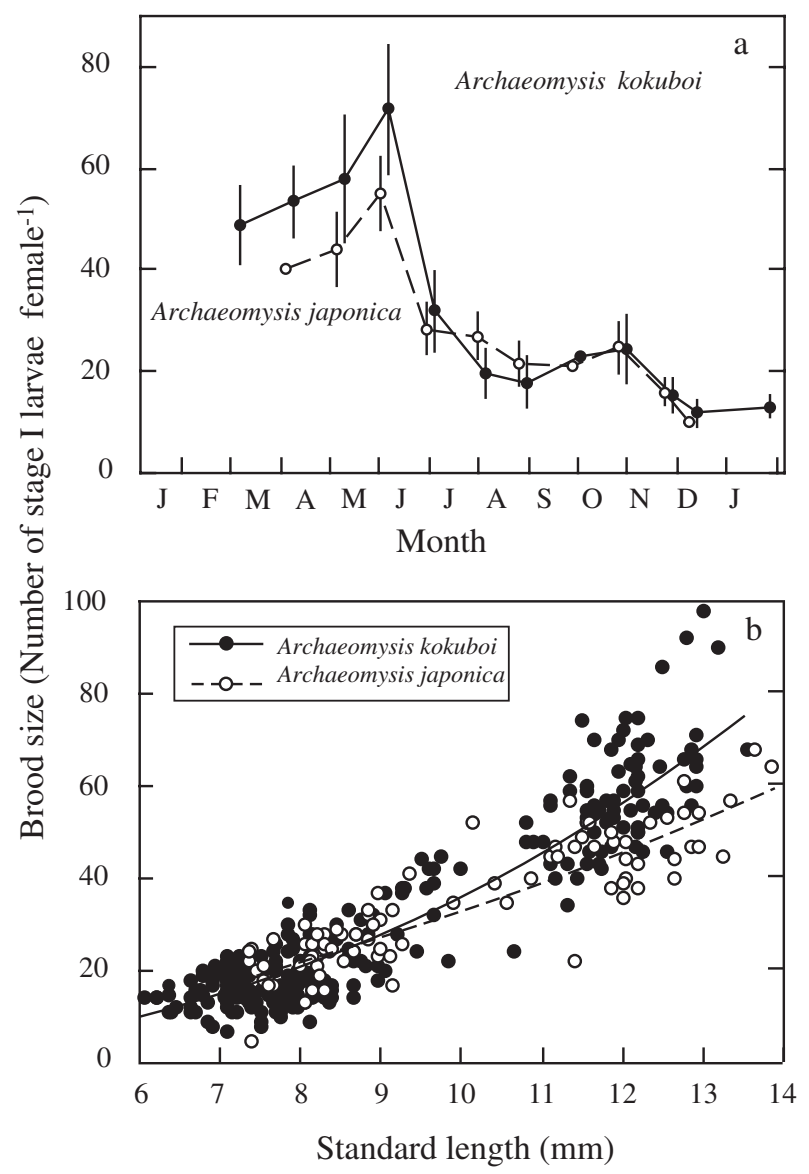

Fig. 4. Archaeomysis kokuboi and A. japonica. (a) Seasonal variation in mean $( \pm \mathrm{SD})$ brood size at Koshirahama Beach in Otsuchi Bay. (b) Relationships between brood size and standard length of brooding females 

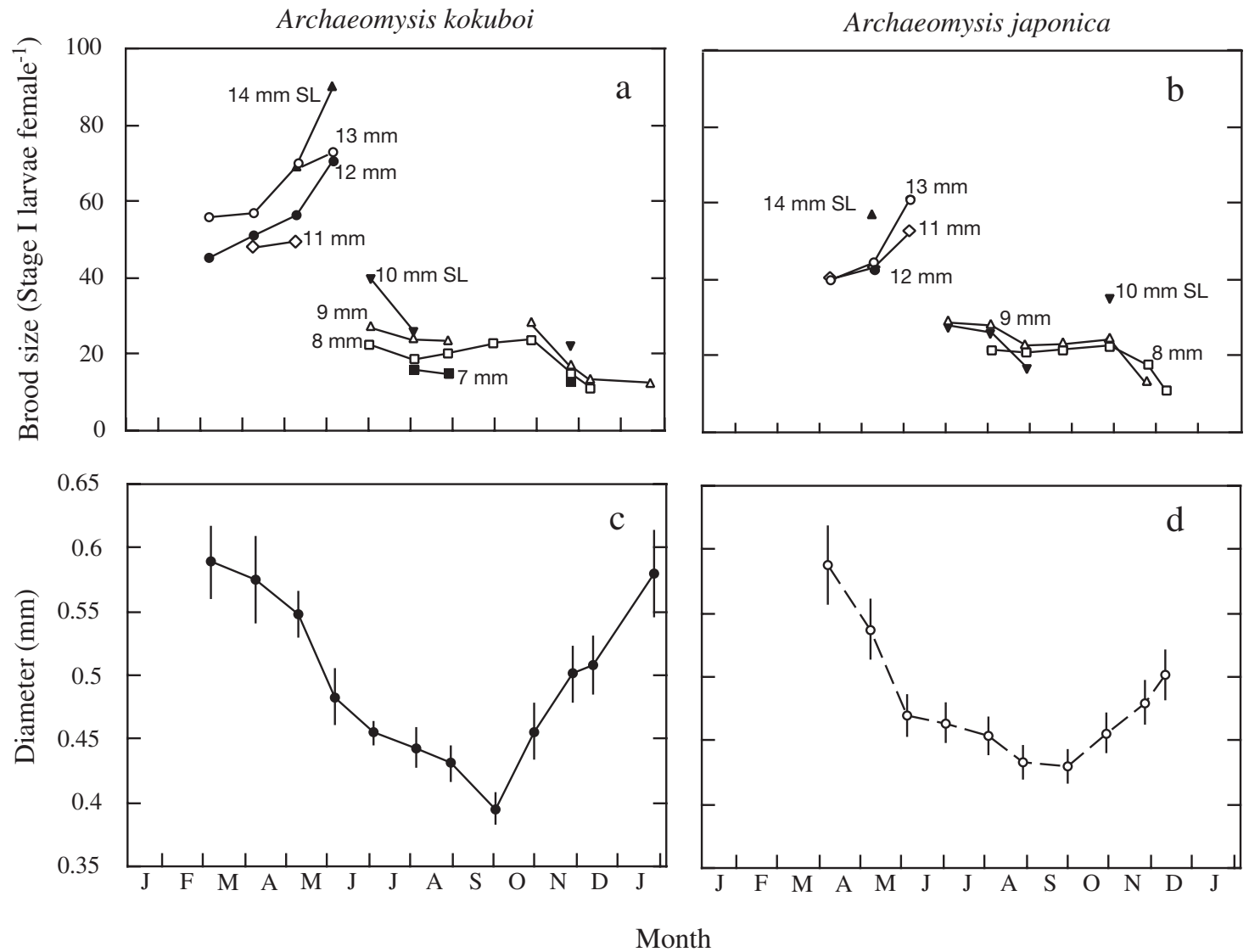

Fig. 5. Archaeomysis kokuboi and A. japonica. Seasonal variation of $(\mathrm{a}, \mathrm{b})$ brood size in different size classes and (c,d) mean diameter of Stage I larvae at Koshirahama Beach in Otsuchi Bay. Vertical bars indicate SD

the exception of summertime (August and September), where the mean ratio decreased to less than 0.3 . However, these values were significantly lower than those in A. kokuboi (ANOVA, $F_{1,225}=12.42$; p < 0.001).

\section{Larval development time}

Total time for larval development $\left(D_{\mathrm{L}}, \mathrm{d}\right)$ decreased exponentially with increasing temperature $(T)$ in both species (Fig. 7a). In Archaeomysis kokuboi, it ranged from $60 \mathrm{~d}$ at $6^{\circ} \mathrm{C}$ to $10 \mathrm{~d}$ at $22^{\circ} \mathrm{C}$ and in A. japonica it ranged from $70 \mathrm{~d}$ at $6^{\circ} \mathrm{C}$ to $10 \mathrm{~d}$ at $22^{\circ} \mathrm{C}$. At lower temperatures, larval development of A. japonica took much longer than in $A$. kokuboi (ANCOVA, $F_{1,14}=$ 8.74; $\mathrm{p}<0.05$ ) and the maximum difference was about $10 \mathrm{~d}$ at $6^{\circ} \mathrm{C}$. The best fit was achieved by using the Belehrádek equation (Eqs. 9 \& 10 in Table 1).

\section{Interval time between broods}

The interval of the brood $\left(I_{\mathrm{B}}, \mathrm{d}\right)$, i.e. the time from the release of juveniles to the extrusion of the next brood

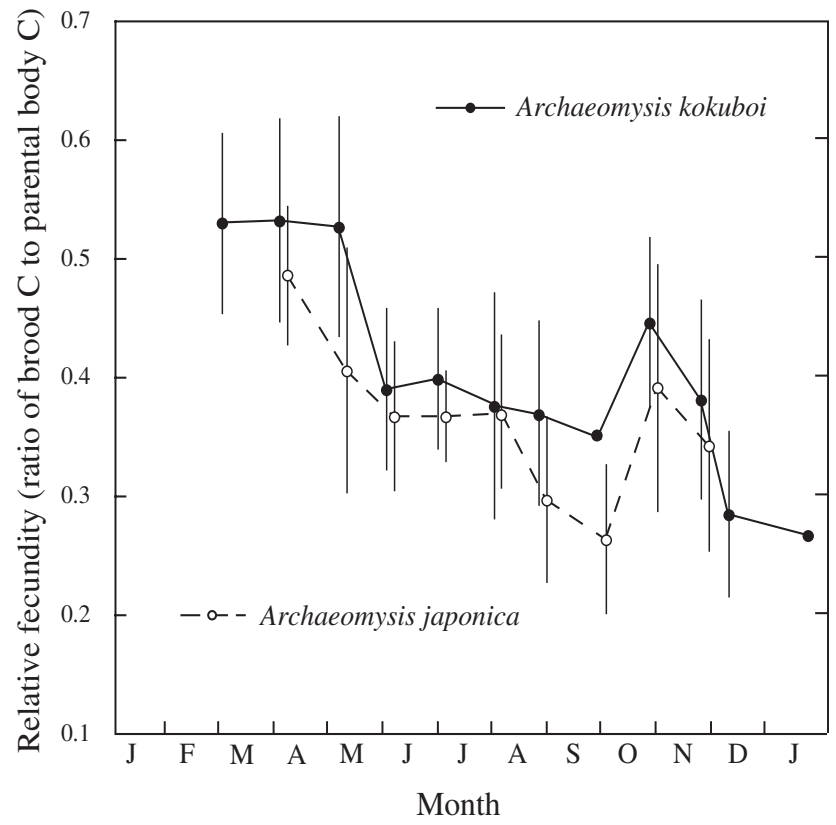

Fig. 6. Archaeomysis kokuboi and A. japonica. Seasonal variation of relative fecundity (ratio of brood $\mathrm{C}$ to parental body C) at Koshirahama Beach in Otsuchi Bay. Vertical bars indicate SD 
Table 1. Archaeomysis kokuboi and A. japonica. Various allometric relationships on their reproductive parameters. Number in the parentheses refer to the equation numbers. Results of statistical difference tested by ANCOVA are also shown. $C_{\mathrm{F}}$ : carbon weight of female; $S L$ : standard length $(\mathrm{mm}) ; L D$ : diameter of Stage I larvae; $T$ : temperature $\left({ }^{\circ} \mathrm{C}\right) ; C_{L}$ : carbon weight of Stage I larvae; $D_{\mathrm{L}}$ : larval development time; $I_{\mathrm{B}}$ : interval between broods; $S L P R$ : specific Stage I larval production rate. ${ }^{*} \mathrm{p}<0.05,{ }^{* *} \mathrm{p}<0.01$, ${ }^{* * *} \mathrm{p}<0.001$, ns: not significant

\begin{tabular}{|c|c|c|c|c|c|c|c|}
\hline \multirow{2}{*}{$\begin{array}{l}\text { Dependent } \\
\text { variable }\end{array}$} & \multicolumn{3}{|c|}{ Archaeomysis kokuboi } & \multicolumn{3}{|c|}{ Archaeomysis japonica } & \multirow{2}{*}{$\begin{array}{l}\text { Statistical difference } \\
\text { by ANCOVA }\end{array}$} \\
\hline & Eq. & $\mathrm{n}$ & $\mathrm{r}$ & Eq. & $\mathrm{n}$ & $\mathrm{r}$ & \\
\hline$C_{\mathrm{F}}(\mathrm{mg})^{\mathrm{a}}$ & $0.0016 S L^{3.05}$ & 91 & $0.987^{* * *}$ & $0.0022 S L^{2.87}$ & 59 & $0.940^{* * *} \quad(2)$ & $F_{1,146}=4.43^{*}$ \\
\hline$L D(\mathrm{~mm})^{\mathrm{a}}$ & $1.06 T^{-0.298}$ & 12 & $0.961^{* *}$ & $1.01 T^{-0.285}$ & 10 & $0.975^{* *} \quad(4)$ & $F_{1,18}=0.90, \mathrm{~ns}$ \\
\hline $\begin{array}{l}B S \text { (number of Stage I } \\
\text { larvae female }{ }^{-1} \text { ) }\end{array}$ & $-17.04+10.62 S L-97.5 L D$ & 263 & $0.944^{* * *}$ & $-13.88+7.01 S L-43.9 L D$ & 88 & $0.884^{* * *}(6)$ & Not applicable $^{c}$ \\
\hline$C_{\mathrm{L}}(\mathrm{mg})^{\mathrm{b}}$ & $0.155 L D^{2.92}$ & 25 & $0.958^{* *} \quad(7)$ & $0.133 L D^{2.80}$ & 30 & $0.963^{* *}$ & $F_{1,52}=10.12^{* *}$ \\
\hline$D_{\mathrm{L}}(\mathrm{d})^{\mathrm{a}}$ & $1398.3(T+0.99)^{-1.62}$ & 9 & $0.998^{* *} \quad(9)$ & $1487.5(T+0.45)^{-1.62}$ & 9 & $0.995^{* *}(10)$ & $F_{1,14}=8.74^{*}$ \\
\hline$I_{\mathrm{B}}(\mathrm{d})$ & $8.3-0.338 T$ & 4 & $0.997^{* *}(11)$ & $8.5-0.343 T$ & 4 & $0.998^{* *}(12)$ & $F_{1,4}=1.73, \mathrm{~ns}$ \\
\hline $\operatorname{SLPR}\left(\mathrm{d}^{-1}\right)$ & $-0.0033+0.00156 T$ & 12 & $0.966^{* *}(13)$ & $-0.0042+0.00139 T$ & 10 & $0.939^{* *}(14)$ & $F_{1,19}=9.79^{* *}$ \\
\hline
\end{tabular}
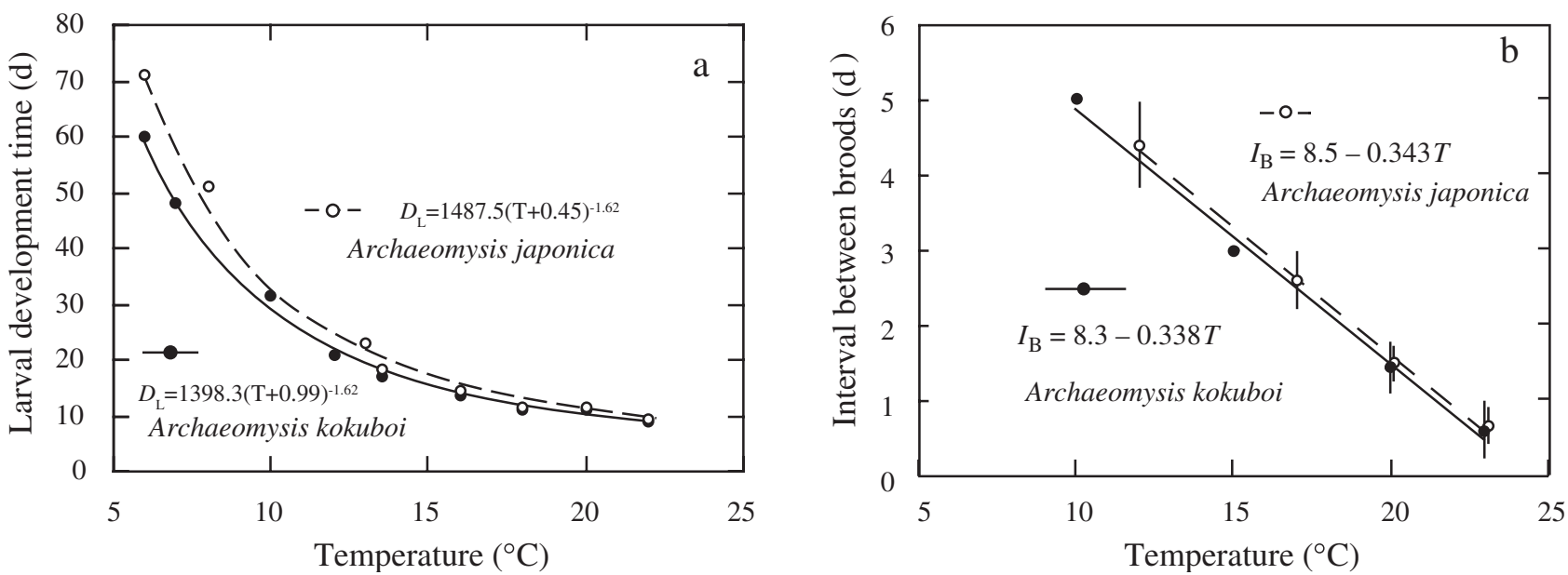

Fig. 7. Archaeomysis kokuboi and A. japonica. Relationships between temperature and (a) larval developmental time and (b) time interval between broods. Vertical bars indicate SD

was significantly related to temperature $\left(T,{ }^{\circ} \mathrm{C}\right)$ in both species (Fig. 7b). In Archaeomysis kokuboi, it ranged from $5 \mathrm{~d}$ at $10^{\circ} \mathrm{C}$ to $0.6 \mathrm{~d}$ at $23^{\circ} \mathrm{C}$ and in A. japonica, it ranged from $4.4 \mathrm{~d}$ at $12^{\circ} \mathrm{C}$ to $0.7 \mathrm{~d}$ at $23^{\circ} \mathrm{C}$. No statistical difference was found between the 2 species (Eqs. 11 \& 12 in Table 1).

\section{Monthly variation in larval production rate}

In both species, in situ Stage I larval production rates $\left(L P R\right.$, number of larvae female $\left.\mathrm{e}^{-1} \mathrm{~d}^{-1}\right)$ were significantly different between Species (2-way ANOVA, $F_{1,325}=$ 30.81; $\mathrm{p}<0.001)$ and Month $\left(F_{9,325}=55.69 ; \mathrm{p}<0.001\right)$, and in the interaction 'Species $\times$ Month $\left(F_{9,325}=8.34\right.$; $\mathrm{p}<0.001)$. In Archaeomysis kokuboi, the LPR in- creased from March (0.9) to early June (3.4), the annual maximum (Fig. 8a). The LPR decreased after late June, but remained at a relatively high level until August, ca. 2 larvae female $\mathrm{e}^{-1} \mathrm{~d}^{-1-1}$. After August, it decreased gradually towards the winter minimum in January, 0.3 larvae female $\mathrm{f}^{-1} \mathrm{~d}^{-1}$ (Fig. 8a). In A. japonica, the $L P R$ showed a similar pattern with that of $A$. kokuboi, but it was constantly $40 \%$ lower than in the former species during spring (ANOVA, $F_{1,101}=8.76$; $\mathrm{p}<0.004)$, April to June. After July, it showed almost the same values as those of $A$. kokuboi (ANOVA, $F_{1,214}=1.55 ; \mathrm{p}=0.21$ ).

Specific Stage I larval production rates $\left(S L P R, \mathrm{~d}^{-1}\right)$ ranged from 0.007 to $0.033 \mathrm{~d}^{-1}$ for Archaeomysis kokuboi and from 0.009 to $0.028 \mathrm{~d}^{-1}$ for Archaeomysis japonica, respectively. When the $S L P R$ was plotted 

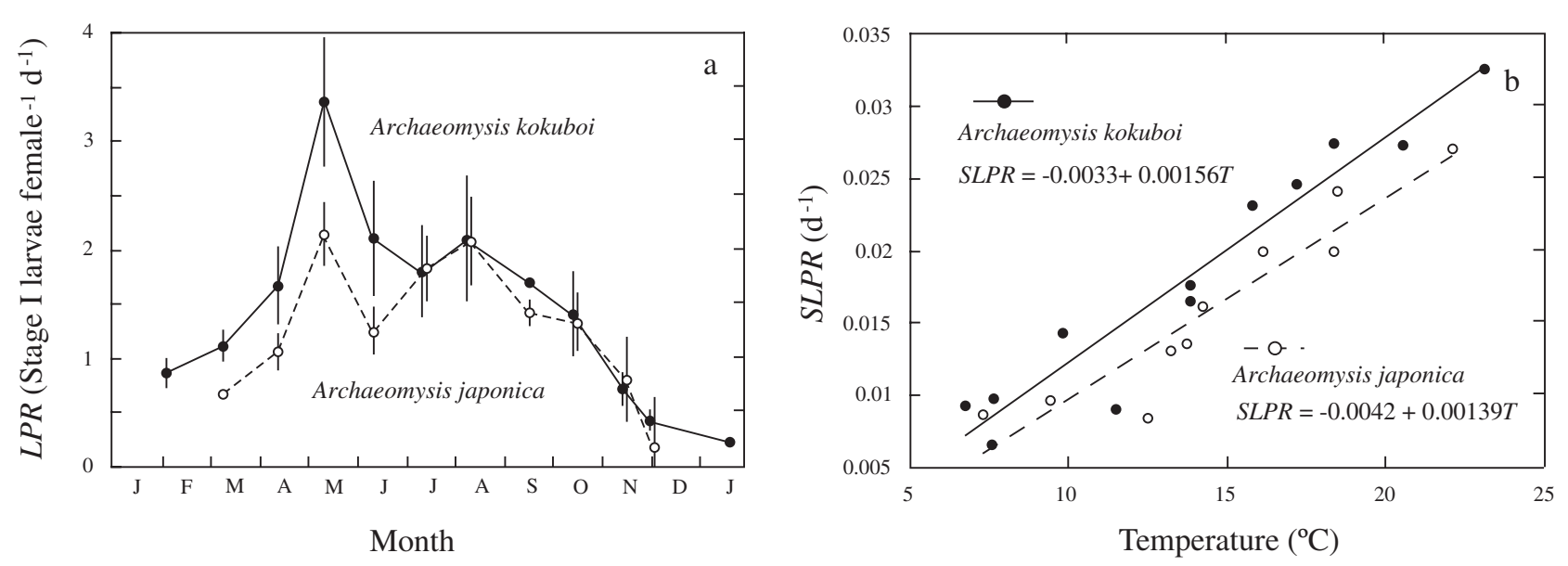

Fig. 8. Archaeomysis kokuboi and A. japonica. (a) Seasonal variation in Stage I larval production rate $\left(L P R\right.$, No. of larvae female ${ }^{-1}$ $\left.\mathrm{d}^{-1}\right)$ and (b) relationships between temperature and specific larval production rate $\left(S L P R, \mathrm{~d}^{-1}\right)$ at Koshirahama Beach in Otsuchi Bay

against temperature, the rate increased linearly with increasing temperature $\left(T,{ }^{\circ} \mathrm{C}\right.$ ) in both species (Fig. 8b). The relationships were significantly different between the 2 species (ANCOVA, $F_{1,19}=9.79 ; \mathrm{p}<0.01$, Eqs. 13 \& 14 in Table 1).

\section{DISCUSSION}

\section{Comparative biology in seasonal reproduction}

Although the physical conditions of the habitats of the 2 species are extremely different, their seasonal reproductive patterns are similar. Both species have 3 breeding peaks within the year during spring to autumn and a low rate or no reproduction in the winter season. Successive increases of the proportion of juveniles after the breeding peaks (Fig. 2) suggest that both species have 3 main generations per year: a largersized overwintering as well as smaller-sized spring and summer generations (Figs. 2 \& 3a). This pattern is typical of the iteroparous mysid species in temperate climates (Wittmann 1984) and has also been found in Archaeomysis spp. (Matsudaira et al. 1952, Hanamura 1999). In general, the seasonal change of adult body size is a phenotypic response to temperature (Toda et al. 1984, Yamada \& Yamashita 2000) and the difference in size at maturity has been suggested to be related to the seasonal variation of mortality of different size classes (Johnston \& Northcote 1989).

The seasonal reproductive patterns of the 2 species, however, showed some noticeable differences which would reflect species-specific reproductive traits. The most conspicuous difference is the length of the breeding period. In Archaeomysis kokuboi, the major breeding period was early March to December and a small number of brooding females were still collected during the winter. On the other hand, the breeding period of A. japonica was more restricted. Probably, the variation of breeding periodicity between the 2 species is due to the difference in their adaptive range of temperature. The geographical distribution range of $A$. kokuboi is limited to northern Japan, in the area between 37 and $43^{\circ} \mathrm{N}$, whereas A. japonica is distributed along the Japanese coast ( 33 to $45^{\circ} \mathrm{N}$ ), where warm currents prevail, at least in summer (Hanamura 1997). Therefore, A. japonica is a warmer water species and its cessation of reproductive activity during winter in Otsuchi Bay is probably caused by the decrease of temperature. Hanamura et al. (1996) reported that a small number of females in a southern population of $A$. japonica (Shijiki Bay, $33^{\circ} \mathrm{N}$ ) were breeding in February and the lowest water temperature of Shijiki Bay, ca. $12^{\circ} \mathrm{C}$ (Kimoto et al. 1987) roughly corresponds to that of late November in Otsuchi Bay when A. japonica breeding finishes (Figs. 1 \& 2).

Mean brood size in the overwintering generation of Archaeomysis kokuboi was consistently ca. $20 \%$ higher than that of $A$. japonica on the same sampling date (Fig. 4). The overwintering generation of $A$. kokuboi showed a considerably higher relative fecundity (50\% on average) and larger body size (3.1 mg C on average) than those of $A$. japonica (43\%, $2.7 \mathrm{mg} \mathrm{C}$ ), resulting in higher brood size in $A$. kokuboi. The higher relative fecundity in the overwintering generation of $A$. kokuboi seems to only occur during the lower temperature period (March to May, $<10^{\circ} \mathrm{C}$ ), since it decreased to the level of A. japonica in early June. In general, investment for first brood of iteroparous mysids commences from 1 to 2 earlier moulting stages before the attainment of sexual maturity (Wittmann 1984). Sudo (2003) observed a decrease in brood size 
with an increase in the number of broods in Acanthomysis robusta at low temperatures and therefore, $A$. kokuboi might be able to invest much more energy into the first brood during spring. On the other hand, the lower relative fecundity in the overwintering $A$. japonica reflects their reduced capability to reproduce during the low water temperature period. The spring/ summer generations of A. japonica, however, exhibited brood sizes comparable to those of A. kokuboi (Fig. 4a), though their relative fecundity was still significantly lower (Fig. 6). The larger size at maturity in the spring/summer generation of $A$. japonica than in $A$. kokuboi probably enabled them to have comparable brood sizes (Fig. 3).

The brood sizes of both species were controlled to some extent by seasonal changes of Stage I larval size, which were inversely related to water temperature (Fig. 5). The effect of larval size variation is noticeable in the overwintering generations of both species, i.e. the brood size of overwintering generations in both species gradually increased from March/April to early June, though the adult size was constant (Fig. 5). During this period, the largest brood size of Archaeomysis kokuboi was recorded in early June when relative fecundity was considerably decreased (Fig. 6). Likewise, the gradual increase in brood size with decreasing relative fecundity was also observed in the overwintering generation of $A$. japonica. This suggests that reduction of the larval size is effective to increase their brood size even if the total reproductive investment is decreased to some extent. This would serve as adaptation to increase their recruitment in the warmer season when the survival rate of juveniles is expected to be high (Wittmann 1984).

In both species, larval development time showed an inverse relation to water temperature (Fig. 7a). It is well known that larval development is strongly related to water temperature (Wittmann 1984). The variation in the duration of larval development observed in this study agreed with the general relationships between temperature and the incubation period in mysids (Wittmann 1984) as well as the previous reports for Archaeomysis kokuboi (Matsudaira et al. 1952, Kaneko \& Okata 1995). At lower temperatures $\left(<13^{\circ} \mathrm{C}\right)$, the development time of $A$. japonica is much longer than that of A. kokuboi (Fig. 7a). The difference in larval development time at low temperature between the 2 species would also reflect their adaptive range to temperature.

Successive broods are known in the majority of mysid species, especially in warm regions, and are produced within 1 or 2 nights after the previous release of juveniles (Toda et al. 1984, Wittmann 1984). This study showed that both Archaeomysis spp. are also iteroparous regardless of generation. However, the interval between broods is not analogous to the general pattern in mysids, i.e. it showed a clear inverse relation to temperature (Fig. 7b). Generally, ovulation and copulation of mysids are coupled with moulting, and the synchronization of these events is attained by moult inhibition (Cuzin-Roudy \& Tchernigovtzeff 1985). In both Archaeomysis spp. at low temperature, however, larval development was completed earlier than the moulting cycle, or production of the next brood took longer than larval development. In any case, early release of juveniles at lower temperature might be adaptive to decrease the mortality due to larval loss during spring when the incubation period is longest.

Specific Stage I larval production rate $(S L P R)$ of both species was significantly related to water temperature (Fig. 8b) and this indicates that in Otsuchi Bay the temperature essentially determines the variation of reproduction rate of both species as shown by laboratory experiments in other mysids with excessive amounts of food (Toda et al. 1984, Yamada \& Yamashita 2000). However, the seasonal variations in the Stage I larval production rate $(L P R)$ were not explained by water temperature. The variation in the $L P R$ probably reflected their seasonal reproductive traits, depending on the 2 different life forms, i.e. overwintering and spring/summer generations. In the overwintering generations, Archaeomysis kokuboi exceeded A. japonica in all reproductive parameters, i.e. larger body size, higher relative fecundity and brood size, shorter incubation period coupled with reduction in larval size with increase of water temperature, all resulting in their high $L P R$ during spring-early summer (Fig. 8a). The maximum $L P R$ in $A$. kokuboi (3.4 larvae $\mathrm{d}^{-1}$ ) recorded in the overwintering generation is considerably higher than those in other warm-season breeding mysids, Neomysis intermedia (1.9; Toda et al. 1984), Leptomysis lingvura (1.2; Wittmann 1984), Acanthomysis mitsukurii (2; Yamada \& Yamashita 2000), as well as A. japonica $(2.1$; this study) and therefore, A. kokuboi is characterized by high reproductive output in the overwintering generation (lower water temperature period). On the other hand, in the spring/summer generations, the $L P R$ of $A$. japonica became comparable to those of A. kokuboi. This attainment was largely caused by the higher acceleration of larval developmental rate with increases in water temperature and their larger body size, which compensated for the lower relative fecundity, resulting in the same level of brood size as A. kokuboi. Although the spring/summer generations of both species showed comparable value in the $L P R$, the $S L P R$ of A. japonica was still lower than that of $A$. kokuboi. Therefore, it is concluded that $A$. japonica exhibits efficient larval production during the higher water temperature period. 


\section{Reproductive traits as adaptations to the respective habitats}

To examine and summarize the general patterns of the reproductive traits of the 2 species of Archaeomysis, we constructed a contour map of the SLPR as functions of body size of brooding females and temperature based on the allometric equations obtained in this study (Eqs. 1 to 12 in Table 1) and in which the mean size of brooding females at each sampling were also plotted (Fig. 9).

The diagrams show that $S L P R$ in both species generally tends to increase with increasing temperature, and to decrease above and below a certain body size at a given temperature (0.9 to $2.7 \mathrm{mgC}$ for Archaeomysis kokuboi, 0.6 to $1.3 \mathrm{mgC}$ for A. japonica; shown as a dotted line in the diagrams). However, as a whole, the gradients among the contours are much steeper in $A$. kokuboi compared with A. japonica and at a given temperature, A. kokuboi retain rather constant SLPR regardless of their body size. These features support

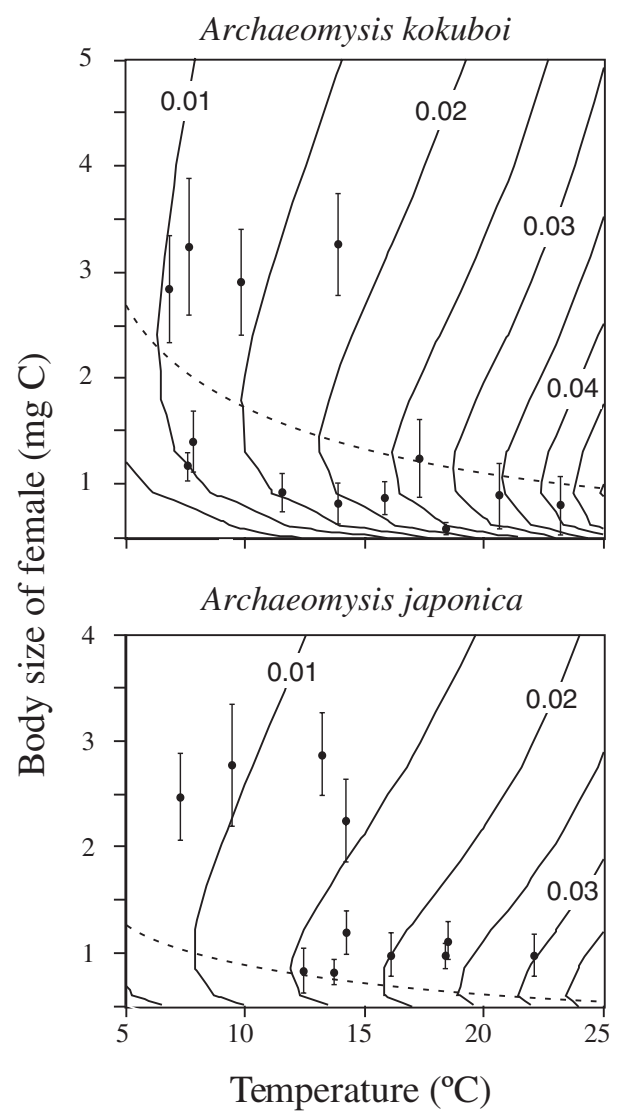

Fig. 9. Archaeomysis kokuboi and A. japonica. Contour plots of the specific larval production rate as a function of water temperature and body size of brooding female. Dots: size of brooding females (mean $\pm \mathrm{SD}$ ). Dashed lines: theoretically highest specific larval production rate at a given water temperature, calculated from equations in Table 1 the idea that $A$. kokuboi is characterized by the retention of a high reproductive activity and particularly their potential to reproduce during the low temperature season is remarkable, resulting in high population density throughout the year. Moreover, the diagram demonstrates that the size at maturity of the spring/ summer generation in the field is somewhat smaller than the expected maximal theoretical sizes of the SLPRS (Fig. 9) and this feature would indicate early maturity to adapt to a habitat characterized by high mortality. High mortality of beach mysids during the summer season is reported in A. kokuboi (Matsudaira et al. 1952). Consequently, the reproductive pattern of A. kokuboi is adaptive to the intertidal zone of sandy beach, which is characterized by high mortality rate caused by unpredictable events such as storms and extreme changes in temperature or salinity.

The diagram for Archaeomysis japonica shows that the reproductive potential is lower both at lower temperature and larger body size, while a higher reproductive rate can be attained under certain conditions, i.e. water temperatures above 12 to $13^{\circ} \mathrm{C}$ and body size about 0.8 to $0.9 \mathrm{mg} \mathrm{C}$. This range clearly corresponds to the size of brooding females of the spring/summer generation in the field. These features support the idea that in Otsuchi Bay, A. japonica maintains its population by efficient larval production during the high water temperature season $\left(>12\right.$ to $13^{\circ} \mathrm{C}$ ) to compensate for their relatively lower $S L P R$ and shorter breeding period. Therefore, the reproduction of $A$. japonica is much more adaptive to the infralittoral habitat where predictable events such as the seasonal variation of temperature are the dominant environmental features.

This study found that Archaeomysis kokuboi retains a higher reproductive effort for an extended period to settle into the intertidal zone of sandy beaches but does not show any specialization to the basic reproductive features such as an altered generation pattern or a change in the size of Stage I larvae. This specification would be true of other intertidal peracarids since the tendency to increase their reproductive effort, such as higher fecundity and extension of breeding period, are often reported (e.g. amphipods; Fish \& Preece 1970, isopods; De Ruyck et al. 1991). Besides the higher reproductive effort, the intertidal macrofauna on sandy beaches expends extra energy for intertidal migration for position maintenance (McLachlan et al. 1979, Takahashi \& Kawaguchi 1997, Kaneko \& Omori 2003), osmotic regulation for variable salinity (Webb et al. 1997), reinforcement of the exoskelton to be resistant to the physical harshness and desiccation (Kamihira 1979, Brown 1982, Takahashi 1996). Despite these extra costs, a high abundance of intertidal macrofauna is common in sandy beach ecosystems, suggesting the existence of favorable conditions in intertidal areas. 
Recently, Defeo et al. (2001) and Defeo \& Martinez (2003) stated that macrofauna, which is well adapted to intertidal sandy beaches is capable of sustaining large populations across a wide spectrum of physical conditions and thus, the physical environment should not be considered the primary factor affecting abundance and life history traits of macrofauna. Probably, intertidal macrofauna on sandy beaches is able to take advantage of the harsh physical features as a benefit to some extent, for instance enhancement of growth and reproduction due to higher water temperature during summer, rich food supply and elimination of certain competitors and predators by wave action (Brown \& Talbot 1972, McLachlan 1983, Itô 1985, Takahashi \& Kawaguchi 1998, Takahashi et al. 2004), and their high reproductive potential is an inevitable feature to restore the population after a catastrophic loss due to unpredictable events such as storms or extreme changes in temperature or salinity.

Acknowledgements. We are most grateful to Captain K. Morita, T. Kawamura and K. Hirano of the Otsuchi Marine Research Center, Ocean Research Institute (ORI) for their help in the field sampling. We thank S. Taguchi of Soka University who provided the facilities of the $\mathrm{CN}$ analyzer. The comments of A. Norkko, Kristineberg Marine Research Station and anonymous referees were gratefully accepted. Thanks are also due to T. P. Hirose and other staff of the plankton laboratory of ORI for the help in the field work and the fruitful discussions during the course of this study. Part of this study was supported by a Research Fellowship from the Japan Society for Promotion of Science for Young Scientists to K.T.

\section{LITERATURE CITED}

Brown AC (1982) The biology of sandy beach whelks of the genus Bullia (Nassariidae). Oceanogr Mar Biol Annu Rev 20:309-361

Brown AC (1983) The ecophysiology of sandy beach animals - a partial review. In: McLachlan A, Erasmus T (eds) Sandy beach as ecosystem. Junk Publishers, Hague, p 575-605

Brown AC, McLachlan A (1990) Ecology of sandy shores. Elsevier, Amsterdam

Brown AC, Talbot MS (1972) The ecology of the sandy beaches of the Cape Peninsula, South Africa. Part 3, A study of Gastrosaccus psammodytes Tattersall (Crustacea, Mysidacea). Trans R Soc S Afr 40:309-333

Cubit J (1969) Behavior and physical factors causing migration and aggregation of the sand-crab Emerita analoga (Stimpson). Ecology 50:118-123

Cuzin-Roudy J, Tchernigovtzeff C (1985) Chronology of the female molt cycle in Siriella armata M. Edw. (Crustacea: Mysidacea) based on marsupial development. J Crustac Biol 5:1-4

Defeo O, Martinez G (2003) The habitat harshness hypothesis revisited: life history of the isopod Excirolana braziliensis in sandy beaches with contrasting morphodynamics. J Mar Biol Assoc UK 83:331-340

Defeo O, Gomez J, Lercari D (2001) Testing the swash exclu- sion hypothesis in sandy beach populations; the mole crab Emerita brasiliensis in Uruguay. Mar Ecol Prog Ser 212: 159-170

De Ruyck AMC, Donn TE, McLachlan A (1991) Life histories and breeding patterns of three intertidal sand beach isopods. PSZN I: Mar Ecol 12:105-121

Diaz H (1980) The mole crab Emerita talpoida (Say). A case of life history patterns. Ecol Monogr 50:437-456

Dugan JE, Hubbard DM, Lastra M (2000) Burrowing abilities and swash behavior of three crabs, Emerita analoga Stimpson, Blepharipoda occidentalis Randall, and Lepidopa californica Efford (Anomura, Hippoidea), of exposed sandy beaches. J Exp Mar Biol Ecol 255:229-245

Ellers O (1995a) Behavioral control of swash-riding in the clam Donax variabilis. Biol Bull 189:120-127

Ellers O (1995b) Discrimination among wave-generated sounds by a swash-riding clam. Biol Bull 189:128-137

Ellers O (1995c) Form and motion of Donax variabilis in flow. Biol Bull 189:138-147

Fish JD, Preece GS (1970) The annual reproductive patterns of Bathyporeia pilosa and Bathyporeia pelagica (Crustacea: Amphipoda). J Mar Biol Assoc UK 50:475-488

Hanamura Y (1997) Review of the taxonomy and biogeography of shallow-water mysids of the genus Archaeomysis (Crustacea: Mysidacea) in the North Pacific Ocean. J Nat Hist 31:669-711

Hanamura Y (1999) Seasonal abundance and life cycle of Archaeomysis articulata (Crustacea: Mysidacea) on a sandy beach of western Hokkaido, Japan. J Nat Hist 33: 1811-1830

Hanamura Y, Jo SG, Murano M (1996) A new species of Archaeomysis from coastal waters of Japan (Mysidacea: Gastrosaccinae). Crustaceana 69:553-566

Ii N (1964) Mysidae, Fauna Japonica. Biogeographical Society of Japan, Tokyo

Itô T (1985) Organisms in sand interstices. Kaimei Sha, Tokyo (in Japanese)

Jo SG, Hanamura Y (1993) Redescription of mysid Archaeomysis vulgaris (Nakazawa, 1910) Comb. Nov. (Crustacea: Mysidacea: Gastrosaccinae). Korean J Syst Zool 9: 103-113

Johnston NT, Northcote TG (1989) Life-history variation in Neomysis mercedis Holms (Crustacea, Mysidacea) in the Fraser River estuary, British Colombia. Can J Zool 67: 363-372

Kamihira Y (1979) Ecological studies of macrofauna on a sandy beach of Hakodate, Japan II. On the distribution of peracarids and the factors influencing their distribution. Bull Fac Fish Hokkaido Univ 30:133-143 (in Japanese with English Abstract)

Kaneko K, Okata A (1995) Biological production process of a mysid (Archaeomysis kokuboi) in the slope of a sandy beach. Tohoku J Agric Res 46:61-71

Kaneko K, Omori M (2003) Diel and tidal migrations and predator-prey relationships of macrobenthic animals in intertidal sandy beaches of Sendai Bay, northern Japan. Benthos Res 58:43-49

Kimoto K, Nakashima J, Morioka Y (1987) Standing stock of chlorophyll $a$ and primary production in a small inlet of Kyushu. Bull Seikai Reg Fish Res Lab 64:35-46

Matsudaira C, Kariya T, Tsuda T (1952) The study on the biology of a mysid Gastrosaccus vulgaris Nakazawa. Tohoku J Agric Res 3:155-174

Mauchline J (1973) The broods of the British Mysidacea. J Mar Biol Assoc UK 53:801-817

Mauchline J (1980) The biology of mysids and euphausiids. Adv Mar Biol 18:1-681 
Mauchline J, Murano M (1977) World list of Mysidacea, Crustacea. J Tokyo Univ Fish 64:39-88

McLachlan A (1983) Sandy beach ecology—a review. In: McLachlan A, Erasmus T (eds) Sandy beach as ecosystem. Junk Publishers, Hague, p 321-380

McLachlan A, Wooldridge T, Van der Horst G (1979) Tidal movements of the macrofauna on an exposed sandy beach in South Africa. J Zool Lond 187:433-442

Souza JRB, Borzone CA (2000) Population dynamics and secondary production of Scolelepis squamata (Polychaeta: Spionidae) in an exposed sandy beach of southern Brazil. Bull Mar Sci 67:221-233

Sudo H (2003) Effect of temperature on growth, sexual maturity and reproduction of Acanthomysis robusta (Crustacea: Mysidacea) reared in the laboratory. Mar Biol 143: 1095-1107

Takahashi K (1996) Ecology of sand-burrowing mysids in Otsuchi Bay, northeastern Japan. PhD thesis, University of Tokyo

Takahashi K, Kawaguchi K (1995) Inter- and intraspecific zonation in three species of sand-burrowing mysids, Archaeomysis kokuboi, A. grebnitzkii and Iiella ohshimai, in Otsuchi Bay, northeastern Japan. Mar Ecol Prog Ser 116:75-85

Takahashi K, Kawaguchi K (1996) Practical key characters to identify the closely related sand-burrowing mysids, Archaeomysis kokuboi and A. japonica (Mysidacea; Gastrosaccinae) throughout all developmental stages. Bull Plankton Soc Jpn 43:113-117

Takahashi K, Kawaguchi K (1997) Diel and tidal migrations of the sand-burrowing mysids, Archaeomysis kokuboi, A. japonica and Iiella ohshimai, in Otsuchi Bay, northeastern Japan. Mar Ecol Prog Ser 148:95-107

Editorial responsibility: Otto Kinne (Editor), Oldendorf/Luhe, Germany
Takahashi K, Kawaguchi K (1998) Diet and feeding rhythm of the sand-burrowing mysids, Archaeomysis kokuboi and A. japonica in Otsuchi Bay, northeastern Japan. Mar Ecol Prog Ser 162:191-199

Takahashi K, Kawaguchi K (2001) Nocturnal occurrence of the swimming crab Ovalipes punctatus in the swash-zone of a sandy beach, northeastern Japan. Fish Bull US 99: $510-515$

Takahashi K, Hirose T, Kawaguchi K (1999) The importance of the intertidal sand-burrowing peracarid crustaceans as prey organisms of fish in the surf zone of sandy beach at Otsuchi Bay, northeastern Japan. Fish Sci 65: 856-864

Takahashi K, Hirose T, Azuma N, Kawaguchi K (2004) Diel and intraspecific variation of vulnerability in the beach mysid, Archaeomysis kokuboi to fish predators. Crustaceana 77:717-728

Toda H, Takahashi M, Ichimura S (1984) The effect of temperature on the post-embryonic growth of Neomysis intermedia Czerniawsky (Crustacea, Mysidacea) under laboratory conditions. J Plankton Res 6:647-662

Veloso VG, Cardoso RS (1999) Population biology of the mole crab Emerita brasiliensis (Decapoda: Hippidae) at Fora Beach, Brazil. J Crustac Biol 19:147-153

Webb P, Wooldridge T, Schlacher T (1997) Osmoregulation and spatial distribution in four species of mysid shrimps. Comp Biochem Physiol A 117:427-431

Wittmann KJ (1984) Ecophysiology of marsupial development and reproduction in Mysidacea (Crustacea). Oceanogr Mar Biol Annu Rev 22:393-428

Yamada H, Yamashita Y (2000) Effects of temperature on intermoult period, growth rate and reproduction rate in Acanthomysis mitsukurii (Crustacea: Mysidacea). Crustac Res 29:160-169

Submitted: February 17, 2004; Accepted: July 15, 2004 Proofs received from author(s): October 21, 2004 